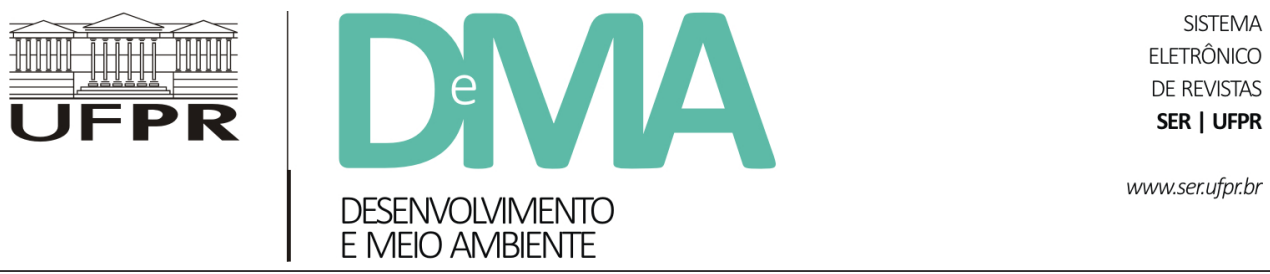

\title{
Homenagem a um economista descalço: Manfred Max-Neef
}

\section{Tribute to a barefoot economist: Manfred Max-Neef}

Ainda que signifique uma perda e que nos entristeça o falecimento do nosso querido "Fred", como era conhecido entre seus amigos mais próximos o professor Manfred Max-Neef, no dia oito de julho deste ano, com 86 anos, suas ideias nos alentam e sobrevivem dentro de nós, pesquisadores que investigam o tema do desenvolvimento e meio ambiente, sobretudo quando compreendido no que remete ao pós-desenvolvimento. Esse termo não pressupõe que haja uma etapa posterior ao desenvolvimento, mas que se reconheçam as críticas em torno dessa ideia, ilustradas no último relatório de indicadores de desenvolvimento humano (ONU, $2017)^{1}$, que aponta que $16 \%$ da população do planeta concentram $67 \%$ da renda bruta. Se ainda não bastasse tal disparidade, os mesmos 16\% que representam os Países com Muito Alto IDH concentram $57 \%$ do lançamento de dióxido de carbono $\left(\mathrm{CO}_{2}\right)$ de todo planeta. Ou seja, o que se convencionou a denominar "desenvolvimento" mais se assemelha a um mau desenvolvimento.
Não há dúvida que tive a sorte de conhecê-lo, ter minha primeira supervisão de pós-doutorado por ele, em 2005, junto ao Centro Transdisciplinar de Estudos Ambientais (CEAM) da Universidade Austral de Chile (UACH). Sempre me recordo da acolhida que recebi na casa 4, no campus Isla Teja, em Valdivia, onde se localiza até hoje o CEAM - um dos lugares mais inspiradores do campus. Aliás, em conversa com Manfred, ele me disse que, assim que chegou a Valdivia, a convite da Universidade, ali tinha sido seu local de residência. A casa 4 tem vista para um rio com o mesmo nome da cidade. Se não me engano, entre tantas conversas e sobre tantos assuntos que tivemos ali, contou que viveu em cerca de 14 países diferentes, um deles o Brasil, onde sua estada durou ao menos 6 meses. Manfred possui uma trajetória que serve de inspiração. Mais que um acadêmico, é um filósofo descalço. Ele não apenas debruçou-se sobre livros e publicou trabalhos, mas vivenciou seus temas de interesse, ou melhor, seus

\footnotetext{
${ }^{1}$ ONU, Organização das Nações Unidas. PNUD, Programa das Nações Unidas para o Desenvolvimento Humano. Informe sobre o desenvolvimento humano 2016. New York: PNUD, 2016.
} 
interesses surgiram a partir de suas escolhas de vida. É um legado digno de ser homenageado.

Tive algumas honrarias agraciadas por Manfred. A primeira foi revisar cientificamente a única tradução de sua obra para o português, Desenvolvimento à Escala Humana, publicado pela editora da Universidade Regional de Blumenau (EDIFURB), em 2012, e também escrever o prefácio dessa edição. Trata-se de um livro para degustar, não apenas para riscar, sublinhar trechos de interesse e fichá-lo. Embora passados quase 40 anos desde que foi lançado na sua edição original em inglês, o livro se transformou em um clássico, pois suas ideias não envelhecem, mas se perenizam. O segundo privilégio foi ter tido um prefácio escrito por Manfred em meu livro Turismo como Fenômeno Humano, publicado pela editora da Universidade de Santa Cruz do Sul (EDUNISC), em 2005. Sempre digo que a leitura do prefácio do Manfred já vale a compra do livro. Por fim, o terceiro foi participar de um livro que o homenageou em vida: Discípulos y colaboradores: testimonios In: Manfred Max-Neef: de un economista, músico y visionário: 80 años. Valdivia (Chile): Universidad Austral de Chile, 2013.

As ideias de Manfred foram muitas, mas duas me parecem que merecem destaque, sobretudo por estarem imbricadas. A primeira é o termo que se produziu no título deste texto "Economia Descalça" e a segunda no já mencionado Desenvolvimento à Escala Humana. Nas palavras do próprio Max-Neef, "a economia existe para servir às pessoas, e não para que as pessoas sirvam à economia" (2011, p. $32)^{2}$, o que sugere pensar em outras economias, além da instituição do mercado.
Existem outras economias, a doméstica, a comunitária, a popular, a pública, além de suas hibridizações, as quais preenchem vazios criados pela instituição do mercado, incapaz de satisfazer as necessidades humanas. Outra crítica à economia de mercado é que, ainda que enaltecida pelos seus simpatizantes por gerar riqueza, é também lembrada pelos seus críticos por produzir pobreza, isto é, ocasiona dificuldades para pessoas possuírem renda econômica que as permitam viver com dignidade.

No entanto, uma perspectiva também inovadora é a crítica de Manfred ao fato de que tais qualificações se restringem ao espectro da economia. O que ele aponta é que há riquezas e pobrezas em outros campos da vida, além da economia. Como riqueza ou pobreza de afeto, de identidade e tantas outras dimensões da existência. $\mathrm{Ou}$, como sugerem os sábios ditos populares, "pobres de espírito" e "ricos em saúde".

Nesse sentido, cabe ressaltar que, em círculos restritos de amigos, Fred comentava que há uma categoria existencial, além das nove publicadas na sua matriz de necessidades humanas - subsistência, proteção, afeto, entendimento, participação, ociosidade, criação, identidade e liberdade - que lhe rendeu, em 1983, o chamado Prêmio Nobel Alternativo (Right Livelihood Award) no Parlamento da Suécia. Essa categoria é a transcendência, o que implica que o significado da vida não se resume meramente a mensurá-la economicamente, como tão bem faz a sociedade de consumo. Não pode tampouco ser medida racionalmente, aprisionando-a aos ditames da racionalidade enquanto restrita à qualidade do pensamento e do comportamento que resulta da

${ }^{2}$ Max-Neef, Manfred. Desenvolvimento à escala humana. Blumenau: Edifurb, 2012. 
adaptação da razão a um contexto pessoal ou, ainda, social (DAMÁSIO, 2000) ${ }^{3}$, sem que haja uma razão governada por valores que dizem respeito à própria existência cosmológica. E que fique claro que esta não fica restrita a seres vivos humanos, mas também a seres vivos não humanos, o que sugere uma visão ecocêntrica.

\author{
Com muitas saudades \\ Carlos Alberto Cioce Sampaio \\ Aluno e Amigo do Professor Manfred \\ Max-Neef
}

\title{
Extrato da biografia de Manfred Max-Neef
}

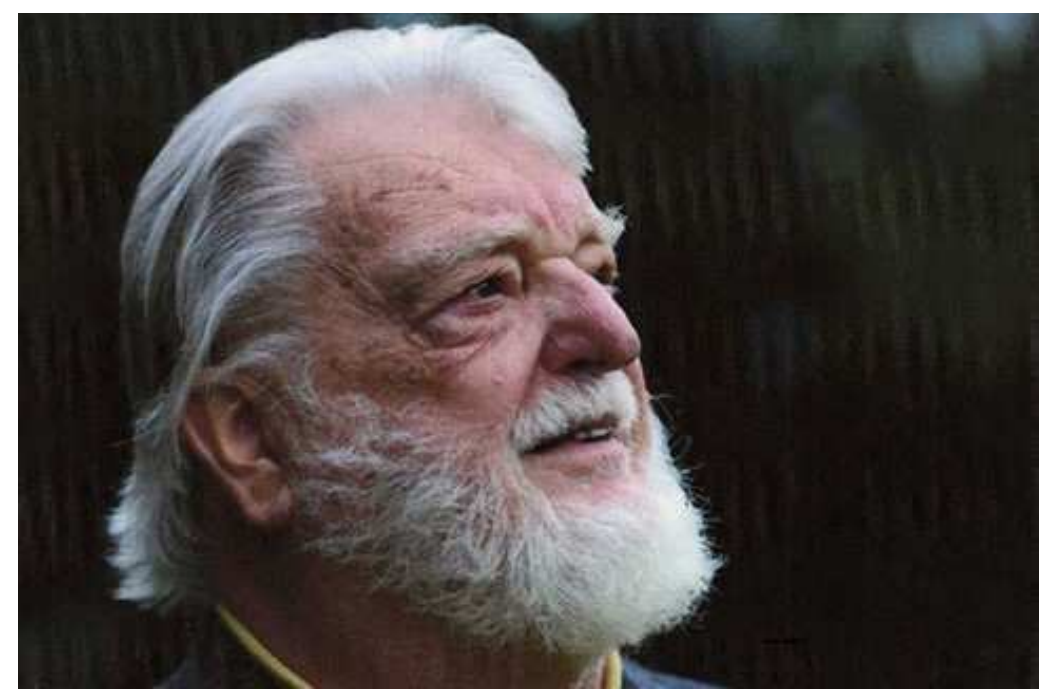

Economista chileno e alemão. Entre seus livros destacam-se Economia Descalça e Desenvolvimento à Escala Humana. Este último destacado pela Universidade de Cambrigde como um dos 50 livros mais importantes do mundo em sustentabilidade. Foi acadêmico da Universidade de Califórnia, Berkeley, no início dos anos 60 e também Professor Visitante de várias universidades dos Estados Unidos, América Latina e Europa. Admirador das ideias do ecossocioeconomista Ernest Fritz Schumacher. Foi fundador e Diretor do Centro de Alternativas de Desenvolvimento CEPAUR, onde foi criada a teoria do Desenvolvimento à Escala Humana, com o apoio da Fundação Dag Hammarskjöld da Suécia. Trabalhou com a OIT e a FAO e foi Reitor da Universidade Austral do Chile entre 1994 e 2002. Em 1983 recebeu o Prêmio Nobel no Parlamento da Suécia. Possui Doutorados Honoris Causa da Jordânia, Colômbia, Argentina e Estados Unidos, além do Prêmio Universitário de Honra mais elevado do Japão. Atualmente era Diretor do Instituto de Economia da Universidade Austral do Chile. Um de seus últimos livros publicados foi em 2011 na Inglaterra: Economics Unmasked: from Power and Greed to Compassion and the Common Good, tendo o destacado físico holandês Philip B. Smith como coautor.

${ }^{3}$ Damásio, Antônio R. Descartes' error: emotion, reason, and the human brain. New York: Harper Collins Pub, 2000. 